5 Research Square

\title{
Master of public health practicum: Global trends and current practices.
}

\section{Hannah Gummeson}

University of Limerick

Sonika Raj Goel

University of Limerick

Khalifa Elmusharaf ( $\square$ khalifa_elmusharaf@yahoo.com )

University of Limerick https://orcid.org/0000-0001-8652-1867

\section{Research article}

Keywords: Practicum, internship experience, placement, graduate public health, experiential learning

Posted Date: April 20th, 2020

DOI: https://doi.org/10.21203/rs.3.rs-23200/v1

License: (1) This work is licensed under a Creative Commons Attribution 4.0 International License. Read Full License 


\section{Abstract}

Background The field of graduate public health (GPH) education currently lacks clear, universal criteria for the integration of practice-based elements into the curriculum. The concept of the 'practicum' is well endorsed and there is a growing recognition that experiential learning is a crucial aspect of career development for the next generation of public health professionals, benefiting not only students, but also the profession and communities it serves. However, many leading academic institutions continue to emphasize research over experiential learning in public health, making practicums much less commonplace in education centers across the globe.

Methods The purpose of this research was to review global best practices in graduate public health program design in order to identify commonalities and use the findings to inform practicum development.

Data collection for this research was entirely web-based. Practicum guidelines from a globally diverse sample of graduate public health programs were reviewed. Data was compiled from universities' websites and available online sources and collated into an Excel file. Descriptive statistics were computed for each study variable.

Results We screened 108 graduate public health programs and 35 eligible programs were included in the study. Results were reported according to prerequisites \& practicum scheduling, practicum contact hours \& duration, credit hours \& overall credit weighting, competencies, supervision, written agreement, objectives \& deliverables, and approach to assessment. This research resulted in 13 recommendations intended to guide graduate public health practicum design. Based on the analysis of current best practice, the recommendations address the following four key domains: practicum design, mentorship \& supervision, learning outcomes and evaluation.

Conclusions This research demonstrates a global recognition of the benefit of practice experience in graduate public health education. However, the integration of practical components into curricula is inconsistent when viewed through a global lens. There is also significant variation in the structure of existing practical components. We propose that this study be utilized as a tool spark a global dialogue about best practices in graduate public health education through the identification common practices and opportunities for improvement.

\section{Background}

Public health is increasingly moving to the forefront of graduate education within the health sector. As many of the relevant educational entities have begun the slow shift to an integrative approach to care, competency in public health is now being recognized as critical to success in many healthcare fields as new members enter the workforce.

Over the past 20 years, the model of graduate education in public health has undergone multiple stages of development. Best practices have rapidly diverged from the traditionalist dialectical teaching approach 
toward one placing more emphasis on student-led learning in competency-based educational models (1). As an example, for certain institutions affiliated with the Council on Education for Public Health (CEPH) (2) or the Public Health Agency of Canada (PHAC)(3), accreditation is contingent on all Masters of Public Health (MPH) students completing a practicum. Capacity building has been the primary motivation behind these changes.

While relatively new to public health education, the value of experiential learning in education is well described in the literature relating to other allied health fields such as medicine, nursing and social work (4-6). Akin to these sectors, public health occurs primarily in the field and it has been demonstrated that experiential learning is critical to capacity building in public health education (7-9). Practice-based learning puts theory into action, allowing students to work toward competency development through the application of theoretical knowledge to real-world issues. These mentored experiences are also critical to career development, providing unique opportunities to develop professional networks, gain experience in different work-environments and collaborate with others in the field of public health (10). This model builds on the traditional research-focused thesis paradigm toward one of implementation science, where the new generation of public health practitioners are supported to develop interdisciplinary skills for multisector engagement in order to move from research to action $(9,11)$.

The growing integration of practice-based learning into graduate public health curricula signals a divergence from the traditional education model. Many graduate public health institutions are beginning to capitalize on this by offering programs with the option of a thesis-based or practice-based culminating project. That being said, there is significant variation in the method of integrating an experience-based component into the curriculum. Multiple different terms are used including practicum, internship, applied practical experience, culminating experience, field placement, residency and professional placement, to name a few. Clearly, there is meaningful diversity here. However, practicum-based programs are still not the norm, especially in Europe. This is evidenced by the vast majority of globally ranked institutions in the region continuing to offer only thesis-based programs, with no practice-based element required. While this approach may have once served a research-driven culture of health care, the future of public health education lies in practice-to-action.

When considering the design of public health programs going forward, it is important to review the current best-practice in graduate public health education. The goal of this review is to a) identify leading graduate public health programs with an integrated practicum, $b$ ) determine current practice for practicum design through a global lens, and c) use the information to make recommendations to inform the design of public health graduate program practicums.

\section{Methods}

This review of graduate public health (GPH) program design was conducted by adapting a methodological framework first described by Arksey and O'Malley (12), and later refined by Levac and colleagues (13). The steps include 1) identifying research questions, 2) identifying all relevant programs, 
3) selecting significant programs, 4) charting the relevant data, and then 5) summarising and reporting the results.

\section{Purpose}

The purpose of the research is to review the structure of GPH practicums using a globally diverse sample in order to identify common themes and inform current practice for practicum design moving forward.

\section{Search Strategy.}

Data collection for this research was entirely web-based. As described in more detail below, potential programs were identified using online university ranking systems and were then stratified by geographical region into ranked lists. To be included in the sample, GPH programs must incorporate a practice-based component into the curriculum. In some instances, the regionally top 10 ranked GPH programs did not include a practice-based component. As such, the goal was to create a sample representing the top 5 practice-based GPH programs in each of the regions identified.

\section{Identifying Relevant Programs}

The goal in data collection was to create a globally descriptive sample of graduate public health programs offering a practice-based component as a requirement in their curriculum. Top ranked GPH programs were divided based on continental hubs in order to ensure a geographically diverse sample. The hubs included were Africa, Asia, Australia, Canada, European Union, South America, United Kingdom and United States. Examination of databases created by World University Ranking 2019 (WUR) and Academic Ranking World Universities 2019 (AWRU) identified the top ten (ranked) institutions in each geographical hub offering graduate public health programs. It should be noted that initial database queries were done using both WUR and AWRU. However, WUR ranking focused at the university level as compared to AWRU, which ranked the graduate public health programs themselves as opposed to the university as a whole. Due to the specificity of the search parameters, we chose to focus our search in AWRU system, although there was significant overlap between the two algorithms.

\section{Selecting the Programs for Inclusion}

Phase two screening and subsequent data collection was based on global AWRU graduate public health program rankings for each respective geographical region. The AWRU was used as a framework to systematically assess the programs offered, starting with the highest ranking the region. Any of the topranked GPH programs not requiring a practice-based component in the curriculum were excluded from the sample. Programs were also excluded if a practice-based component was mentioned but information was unavailable through a) university website, b) program website, c) student prospectus, d) graduate handbook, e) student guide or $\mathrm{f}$ ) practicum guide. Search parameters are outlined in a PRISMA chart (Figure 1). 
Data collection for eligible programs involved searching GPH program websites for available information about the practice-based component. Information about the program and the practice-based component was downloaded and stored in a series of electronic files. In order to collect data in a systematic fashion, an electronic abstraction proforma was created in Excel. Information on each practice-based component was reviewed and the data was entered into a master file comparing all the selected institutions based on domains of interest. The lead author was responsible for screening the programs using the inclusion and exclusion criteria. The co-authors were then consulted at regular intervals during the review process to discuss the emerging results, and to resolve any issues arising in the search process.

\section{Sample}

We screened 108 graduate public health programs. Our search strategy yielded 40 graduate public health programs representing all continents across the globe. Due to lack of translation support at the time of data collection, 5 schools in Chile, Brazil, Mexico and Puerto Rico were excluded, leaving 35 GPH programs in the sample.

\section{$\underline{\text { Measures }}$}

Data was collected on the duration, timing, credit and contact hours of the program practice-based component, as well as data on preceptor requirements, prerequisites, objectives, deliverables and methods of evaluation of the practice-based component. This study was considered exempt from institutional ethical board review as it did not involve human subjects.

\section{Analysis}

Data was compiled from available online sources and collated into an Excel file. Descriptive statistics were computed for each study variable and are presented in the following section.

\section{Results}

\section{Characteristics of Public Health Programs Reviewed}

Data was collected on the duration, timing, credit and contact hours of the program practice-based component, as well as data on preceptor requirements, prerequisites, objectives, deliverables and methods of evaluation of the practice-based component.

As seen in Table 1, the programs included in the sample compose a snapshot representing the global diversity of GPH programs being offered. Not only is there great geographical diversity but also a variety of accrediting body's that graduate public health (GPH) programs may affiliate with. Of the sample institutions with accredited programs, the majority $(n=6)$ received accreditation through $C E P H$, while others maintain accreditation through Agency for Public Health Education Accreditation (APHEA) $(n=3)$, Netherlands Flemish Accreditation Organization (NVAO) $(n=2)$ as well as International Union for Health Promotion (IUHP), Training Program in Epidemiology and Public Health Interventions Network 
(TEPHINET), and several national ministries of education (collective $n=4$ ). The majority of the programs were not accredited $(n=20,57 \%)$. In terms of overall program structure, program duration followed a bimodal distribution, with $34 \%$ of programs requiring minimum 12 months for completion and $66 \%$ requiring 13-24 months.

Table 1. Characteristics of Universities reviewed $(n=35)$

\section{Structural Characteristics of GPH Practicums}

\section{Prerequisites \& Practicum Scheduling}

Approximately one third of the programs evaluated $(n=11,31 \%)$ specifically outlined prerequisites to be completed prior to the initiation of the practicum. The remainder of the programs ( $n=24,69 \%)$ did not list prerequisites in any of the available course information. However, some of these schools may have accounted for that omission through practicum scheduling. The majority of programs $(n=24,68 \%)$ stipulated that the practicum could only take place after a minimum of two terms were completed (i.e. summer semester in 12-month programs, semester three or four in 16-24 month programs).

\section{Practicum Contact Hours \& Duration}

As seen in Table 2, there was significant variation in required practicum duration with a range measured both in hours or weeks depending on the institution. For placements measured in hours, two (6\%) of the practicums were in the range of $50-100$ hours, four (11\%) were in the range of 101-200 and one (3\%) was in the range of 201 or more hours. For placements measured in weeks, three (9\%) were between 4-8 weeks, nine (26\%) were between $9-12$ weeks and $6(17 \%)$ were between $13-16$ weeks. Ten $(28 \%)$ of the practicums did not have a defined time requirement.

In terms of contact hours, a significant portion of the institutions reviewed (49\%) did not specify a number of contact hours to be completed within a set duration placement duration measured in weeks. Additionally, over a quarter of programs (28\%) did not specify a required contact time at all. Of those that did specify a finite number of contact hours (23\%), six stated only the minimum number of contact hours required whereas the other two gave both the minimum and maximum hours required.

\section{Credit Hours \& Overall Credit Weighting}

As seen in Table 2, one, (3\%) of the practicums reviewed did not earn any credit hours and two (6\%) programs did not provide a credit-hour equivalency for the practical component in the course information. The vast majority ( $91 \%$ ) of practicums reviewed had a fixed number of credit hours associated. The units of measurement of the credit hours were varied, but included credits, credit hours, weighted marks and ECTS (European Credit Transfer System) credits. 
Table 2. Structural Characteristics of GPH Practicums reviewed $(n=35)$

\section{GPH Practicum Domains}

In addition to analyzing the operational elements of practicum design, data collection also focussed on core domains including a) competencies, b) supervision, c) written agreement \& objectives and d) assessment.

\section{Competencies}

As seen in Table 3, most $(n=20,57 \%)$ of the GPH programs reviewed had a published list of core program competencies. The competencies associated with programs offered by the North American institutions are derived from national standards developed by CEPH and PHAC. In other centers, core competencies were institution-specific. The remainder of the sample $(n=15,43 \%)$ did not list program competencies.

In addition to program-centered competencies, several centers also defined practicum-specific competencies. Eight (23\%) of the practicums had clearly listed competencies that guided development of the practicum deliverables and one (3\%) referenced practicum-specific competencies without further definition of their content. However, for the majority of practicums (74\%), no practicum-specific were included in any of the course guidelines available. It is unclear if these programs had not developed practicum-specific competencies or if they were not listed in the available program documentation.

Table 3. Domains of GPH Practicums reviewed $(n=35)$

\section{Supervision}

As seen in Table 3, institutional oversight into practicum supervisors occurred at several levels, both through definition of eligibility criteria and supervisory responsibilities. Approximately one third (37\%) of practicums had stated criteria used to define appropriate preceptors as outlined in Table 4, whereas the majority $(67 \%)$ did not provide criteria or the information was not listed. A similar proportion of programs (34\%) clearly stated the responsibilities of the supervising preceptors, but the majority (66\%) did not.

Table 4. Practicum Supervisor Requirements $(n=13)$ 
Over one third (40\%) of the programs required a written agreement be in place before the student could begin working on the practicum. This was a universal requirement in the North American programs $(n=10)$ however, approximately two thirds of programs in the sample $(60 \%)$ did not reference any form of written agreement as a requirement for the practicum In terms of practicum objectives, the majority of programs provided a defined list (83\%), however only one third (34\%) of institutions reviewed contracted these objectives into a learning agreement. All of the practicum written agreements outline some specific deliverables to be completed and used as part of the assessment metric. The majority (83\%) required students to submit or present a product at the conclusion of the practicum. Of all 35 practicums reviewed, six $(17 \%)$ had no stated final deliverables, three $(8 \%)$ required a portfolio or reflection, five $(14 \%)$ required a poster or abstract, $13(37 \%)$ required an oral presentation, $16(46 \%)$ required 'practicum-specific deliverables' and 17 (49\%) required a written report. It should be noted that one practicum may have had a combination of multiple deliverables required.

\section{Approach to Assessment}

As seen in Table 3, of those practicums which listed the grading information, eight (23\%) were graded on a pass/fail basis and seven (20\%) were evaluated using a letter grade system. All programs listed assessment criteria however the majority in this sample (57\%) did not provide specify if the practicum was graded or a for-credit component. The majority of the practicums $(74 \%)$ had defined assessment intervals with $40 \%$ requiring a pre-placement assessment i.e. learning agreement, $26 \%$ requiring an interim assessment and $60 \%$ requiring a post-placement assessment. Assessment information was not available for nine $(26 \%)$ programs.

\section{Definitions \& Terminology.}

As seen in Table 5, the language used to describe the 'practicum' component was quite diverse across all the graduate public health programs assessed. The term practicum or workplace practicum was most common (40\%), internship was the next most common term (20\%) and placement was also used by several programs (8\%). Other less commonly used terms include applied practical experience (APE), residency, professional practice or project and field work.

Table 5. Descriptive Terminology for Practical Placements $(n=35)$

\section{Discussion}

When considering the design of public health programs going forward, it is important to review recent developments in order to establish current best-practice in graduate public health education. 
Practical placements are extremely beneficial to students $(10,14)$, as evidenced by their integration into many of the leading public health masters programs worldwide. However, this review demonstrated significant variation in practicum design, use of guidelines and accreditation between the programs reviewed. Overall, there were several interesting trends identified in the data that warrant further discussion.

\section{Practicum Design}

One interesting trend is the apparent continental discrepancy in practicum design. A significant proportion of the institutions ranked in the global top 10 for each region reviewed, especially North America, Australia and Africa, integrated a practice-based component into their GPH programs. However, many of the 'leading' programs screened for this review were thesis based. This was of particular note in Europe, where the trend diverges, and we see that the 'top-ranked' programs are all thesis based. These programs have not yet progressed to incorporate a mandatory practice requirement into their education model, when the evidence clearly indicates the many benefits of practicums. There are programs in the European context that do have a practical element however, it is clear that the European institutions diverge from the global trend in GPH program design.

Although practicums are becoming more ubiquitous in graduate public health education, as described in this paper, there is significant variation in the methods by which academic institutions integrate a practice-based component into their MPH programs. In the North American context design is highly regulated, where $\mathrm{CEPH}$ and PHAC have issued explicit guidelines that dictate the design of GPH practicums. However, the public health community has yet to develop a clearly defined and globally accepted set of guidelines outlining a superior practicum scheme. Ultimately, there are many different designs that achieve a similar end goal, with institutions around the world developing practice-based components that meet the needs of the communities being served and the people they intend to educate. In this way, practicums are being used as a response to the need for social accountability in health professional education $(15,16)$. While this variation poses a logistic challenge to implementing quality measures in public health education, it also emphasizes the need to integrate flexibility into program design to ensure the needs of both students and communities served are being met.

A current example of emerging innovation in GPH practice-based education is the virtual practicum. It has been suggested as a pioneering solution to meet the needs of GPH students in distance learning programs or those who are pursuing an GPH in parallel with an existing career(17). While the virtual practicum design is not yet widely integrated into GPH practicums on a global scale, it is reasonable to anticipate that this approach will become more commonplace in years to come.

\section{Practicum Design Guidelines}

Another finding of note relates to the global variation in guidelines for practicum design. Some institutions are operating off a national standard which defines the required elements of a practice-based experience( 2,3$)$, but many are not. It is likely that the diversity of 'practicum types' encountered in this 
review is due in large part to the regional variation in design standards. For example, institutions in North America follow clear guidelines set out by CEPH \& PHAC and GPH programs in India follow a national set of recommendations which inform practicum design. Conversely, the majority of programs in other centers seem to rely on community need or working group recommendations to guide the practicum design. Based on our review, it is unclear if creating an 'international standard' is feasible as there is such diversity in educational needs. However, there may be a role for a generic international metric outlining the core elements that must be included in order for a placement to be considered a practicum. This area merits further evaluation.

\section{Accreditation}

Accreditation often provides a clear set of guidelines defining the expectations for program design. There are multiple accrediting bodies, some being public health institutions and others general education institutions, operating both at national and international levels. It is reasonable to infer that institutions being accredited by public health bodies have programs that are more specifically tailored to the needs of public health education as opposed to those that aren't. However, the majority of programs reviewed were not accredited at all. This variation in accreditation status raises the question of necessity of guiding principles in practicum design. Perhaps an interesting example to consider is the Canadian context. In Canada, the majority of programs are not accredited however they are required to meet the MPH practicum guidelines as defined by PHAC. This effectively has the same outcome as following criteria set by an accrediting body. Currently it is unclear if universal accreditation would be useful for GPH programs given the diverse needs profile of the global community. It remains to be seen if accreditation itself is a necessary or if the value accreditation lies in the oversight and provision of vetted guidelines. This area merits further investigation.

\section{Current Practice}

Our comprehensive review of graduate public health (GPH) practicum designs around the world has informed the development of an initial framework of recommendations based on current best practice (Table 6). The following discussion will focus on the elements identified as critical when considering the design of an GPH practicum.

\section{Learning Contract}

The learning contract (LC) is a crucial element to the success of a practicum. The LC is a memorandum of understanding between the student, academic institution and host institution that defines the objectives, expectations and deliverables necessary for successful completion of the placement(18). Practicums are often structured differently, as we have seen in our sample and there can be significant variation in the objectives defined and competencies assessed. Nonetheless, a well-designed LC is key to the success of any practicum. The goal is to clearly translate required competencies into specific 
objectives that will result in deliverables the student will be able to produce during their practical placement. Well-defined, specific practicum guidelines and objectives should be developed internally, based on competencies established by the university and any relevant accrediting body. These competencies must be clearly communicated to students and are used to define the aptitudes a student must acquire prior to completion of the program. Agreement on objectives is essential, not only for the students but also host institutions, in order to ensure the practicum is beneficial to all parties involved(19). In addition, the roles and responsibilities of each partner must be clearly delineated in the LC. This includes specific agreement about honoraria, data ownership, research products and authorship of publications.

\section{Prerequisite Competency Training}

In addition to the development of a clear learning contract, GPH programs should clearly outline the requirements students must meet in order to be prepared to undertake a practicum. We found that some programs clearly state the prerequisites, while in others it is inherent in the program scheduling i.e. students must complete 1 year of classes before they are able to proceed. This was a point of interest identified in our review. It highlights the institutional assumptions being made regarding ethical competence of students. While many programs emphasize prerequisites that focus on epidemiology and biostatistical analysis, there is little emphasis on the need for ethics training in practicum-based programs. This is in contrast to thesis-based programs which consistently integrate the need for ethical approval of research projects into the project authorization process.

\section{Competency-based Training}

It is important that institutions define the public health competencies that their graduates will attain following program completion. Some programs reviewed define key competencies based on frameworks created by an accrediting body such as CEPH, PHAC or $\operatorname{APHEA}(2,3,20)$, while others developed competencies based on internal standards. It should be noted that while the specific competencies assessed varied, there were consistent themes between accredited and non-accredited institutions. Competencies must be clearly communicated to students and are used to define the aptitudes a student must acquire prior to completion of the program. Once competencies are outlined by the institution, best practice is to use these educational outcomes to create practicum objectives. Objectives are actionable goals developed by the student in conjunction with the onsite practicum supervisor and university-based practicum coordinator. Objectives can then be used to inform the development of specific practicum deliverables i.e. what the student will achieve during the practicum placement (Table 6). Current best practice is consistent with the literature in requiring that deliverables are a) of use to the host institution and b) meet the criteria determined by the competency-based practicum objectives (21). While competency acquisition can be difficult to assess, the LC is a key tool that can be used to measure a student's competency development over the course of the program and practicum. One of the main goals 
of LC implementation is to ensure that the students' learning experience will lead to competency building consistent with program expectations.

Table (6) Relationship between competencies, objectives \& deliverables in practicum design

\section{Practicum Supervisor Requirements}

The definition of supervisor requirements is another area that must be addressed in the design of a new GPH practicum. Clear definition is essential to ensure that practicum supervisors a) are qualified to supervise, b) have the skillset necessary to be a public health mentor and c) have capacity to evaluate students' competency attainment. Many of the institutions reviewed reference the need for a preceptor, and some outline specific qualifications necessary. However, the challenge in this area is that qualifications may be highly practicum-specific, with extensive variation in qualifications between medicine, epidemiology, community intervention and program evaluation. For this reason, many programs have very vague supervisor requirements, stating that preceptors must be 'experts in their field'. It is clear that supervisors must be qualified and that the requirements must be well defined such that a potential supervisor can be made aware of the expectations around their role in guiding the student through the practicum process. While the development of precise guidelines is effectively precluded by the extensive potential variation in practicum experience, as many practicums may take place outside the institutional setting, the creation of clear guidelines is critical to ensure both student and supervisors are well prepared to successfully complete the practicum. We recommend that institutions define supervisor requirements in a general sense, as seen in many of the North American centers reviewed . In this way, centers allow for variation in supervisor experience while ensuring that each is qualified to provide project-specific support/oversight to a student in the field.

\section{Effective Mentorship \& Evaluation}

Open communication and continuous student feedback are critical to the success of practical placements. This emphasizes the importance of the role of the practicum supervisor and the need for continuous assessment $(22,23)$. The supervisor plays a dual role in the practicum, both as a mentor and evaluator(24). It is the responsibility of the supervisor to work with the student to ensure that they are operating within the scope of their learning contract and are able to complete any stated deliverables within the timeframe agreed. We recommend conducting periodic evaluations of the students and the placement to assess if the practicum is an appropriate tool to facilitate competency building as required by the program(25). In addition, as the evaluations must be tailored to fit the design of the practicum, it is recommended that both short and long-term assessments are completed from multiple perspectives. While evaluation of student performance is essential to competency development, it is equally important that students are able to assess their supervisors and remain in contact with their home school 
throughout the duration of the practicum should they need support. This emphasizes the importance of the role played by the practicum coordinator. The coordinator is a designated faculty member whose role, among other things, is to ensure the lines of communication between student and institution remain open for the duration of the practicum. Based on our review, the use of periodic evaluation is commonplace in current practicum designs. In addition, many programs reviewed required assessments be carried out by key stakeholders (students, supervisors, host organization) at mid and final term. These assessments should evaluate both the placement and the student performance.

Strengths and weaknesses of this study.

The major strength of this review is that it is based on a global sample of GPH programs, allowing for a unique perspective on the current practice in public health graduate program design. As this has not been done before, this work may serve as an initial foray into the evaluation of global trends in GPH educational approach. The information gathered has been used to design a proposed set of recommendations to guide future practice. This review can also be used to identify areas in GPH program design that could benefit from further evaluation.

There were a number of limitations in this review. Foremost among them, information collection was restricted by what was publicly available on program websites. In addition, programs were identified based on world ranking systems. While these systems operate off specific methodologies, it is likely discrepancies exists between the assessment algorithms which could easily lead to an incompletely representative sampling. In addition, the sample was limited to programs offering information available in English which led to the exclusion of institutions in Central and South America.

\section{Conclusions And Recommendations}

In 2008, Cashman \& Seifer (26) described practice-based or experiential learning as 'an effective and appropriate vehicle for teaching public health and developing public health literacy'. After over a decade of development in public health education, this was an opportunity to revisit the statements made in 2008 and reflect on the degree to which we have be able to align public health education with competency building through practice. The goal in undertaking this review was to develop a deeper understanding of the current practice in graduate public health program design, relating to the structure of the practice-based component.

This analysis offers a description of current global best practices in practicum design for graduate public health (GPH) education. We have shown that there is meaningful variation in the approach to GPH practicum design, with a significant proportion of the leading public health education centers across the world emphasizing the practical elements of training. This speaks to the growing value of practice-based training in the global public health community.

Currently, there are no global criteria that define the key elements necessary to guide the design of successful graduate public health practicums. While variation is expected given the different needs 
profiles seen in a global context, we feel that a general set of guidelines could be beneficial to ensure programs are all meeting a high educational standard.

Based on our review of current best practice, we have developed a set of thirteen recommendations intended to guide the development and design of GPH program practicums:

\section{Design:}

1. Development of clear practicum prerequisites in order to ensure students are equipped with sufficient ethical and theoretical background knowledge in order to successfully complete a practicum placement

2. Practicum scheduling reflects the completion of practicum prerequisites i.e. 2 nd term

3. Develop a learning contract i.e. a memorandum of understanding between the student, academic and host institutions that defines the objectives, expectations and deliverables

4. Develop a comprehensive practicum handbook

\section{Mentorship \& Supervision:}

5. The required qualifications for practicum supervisors are clearly defined by the program

6. The responsibilities of practicum supervisors and coordinators are clearly outlined

\section{Learning Outcomes}

7. Public health competencies are defined by the academic institution. Competencies describe the essential knowledge, skills and attitudes necessary to practice public health. This may be in alignment with those competencies defined by an accrediting body.

8. Competencies are used to create practicum objectives or 'learning outcomes' which are actionable goals developed in collaboration with student, supervisor and coordinator

9. Objectives inform the development of practicum-specific deliverables i.e. what the student will achieve during placement

10. Deliverables must be a) of use to the host institution and b) meet the criteria determined by competency-based practicum objectives

\section{Evaluation:}

11. Practicum placements should be assessed on a 'for credit' basis

12. Learning contracts and supervisor evaluations are used as a metric to determine if the student has completed the deliverables to a professional standard and as agreed

13. Final assessment is a collaborative effort between the practicum supervisor and coordinator

The evidence is there supporting the utility of practice-based education and we would recommend that the public health education community continue to shift toward integration of practice-based experiences 
into GPH programs worldwide.

\section{List Of Abbreviations}

\begin{tabular}{ll} 
APE & Applied Practical Experience \\
\hline APHEA & Agency For Public Health Education Accreditation \\
\hline AWRU & Academic Ranking World Universities \\
\hline CEPH & The Council On Education For Public Health \\
\hline GPH & Graduate Public Health \\
\hline IUHP & International Union For Health Promotion \\
\hline LC & Learning Contract \\
\hline MPH & Masters Of Public Health \\
\hline NVAO & Netherlands Flemish Accreditation Organization \\
\hline PHAC & The Public Health Agency Of Canada \\
\hline TEPHINET & Training Program In Epidemiology And Public Health Interventions Network \\
\hline WUR & World University Ranking
\end{tabular}

\section{Declarations}

\section{Ethics approval and consent to participate}

Not applicable, the manuscript does not report on or involve the use of any animal or human data or tissue.

\section{Consent for publication}

Not applicable, manuscript does not contain any individual person's data in any form.

\section{Availability of data and materials}

All data generated or analysed during this study are included in this published article

\section{Competing interests}

The corresponding author is a member of the editorial board of this journal. The authors declare that they have no further competing interests 


\section{Funding}

No external funding was applied for or used in the conduct of this research. The Graduate Entry Medical School GEMS at University of Limerick funded this article. The funder had no role in construction, evaluation, manuscript preparation or decision for publication.

\section{Authors' contributions}

KE conceived the basic idea for the research. HG conducted early scoping searches, returning to KE and SRG at intervals for advice. HG developed the detailed plan for conduct of comprehensive searches. Any difficulties with search process arising were discussed with KE at regular intervals.

HG summarised all data found and presented it to KE and SRG for comment and feedback.

$H G$, SRG, and KE have made substantial contributions to conception, design, drafting the manuscript and revising it critically for important intellectual content. All the authors have read and approved the final manuscript.

\section{Acknowledgements}

Not applicable.

\section{Authors' information}

Hannah Gummeson is a medical student at University of Limerick Medical School and a research assistant at the Public Health Master program at University of Limerick. Sonika Raj Goel is a postdoctoral researcher at the Public Health Master program at University of Limerick. Khalifa Elmusharaf is a senior lecturer in public health and the director of the Public Health Master program at University of Limerick.

\section{References}

1. Frenk J, Hunter DJ, Lapp I. A renewed vision for higher education in public health. Am J Public Health [Internet]. 2015;105(S1):S109-13. Available from: https://search-proquestcom.proxy.lib.ul.ie/docview/1659937644/fulltextPDF/452267FF7E664376PQ/1?accountid=14564

2. CEPH. ACCREDITATION CRITERIA [Internet]. 2016 [cited 2019 Dec 1]. Available from: www.ceph.org

3. PHAC. CORE COMPETENCIES FOR PUBLIC HEALTH IN CANADA Release 1.0 [Internet]. [cited 2019 Dec 1]. Available from: https://www.canada.ca/content/dam/phacaspc/documents/services/public-health-practice/skills-online/core-competencies-public-healthcanada/cc-manual-eng090407.pdf

4. Kelly $T$, Lazenby M. Developing and validating learning domains, competencies, and evaluation items for global health clinical immersion practicums for graduate-level nursing programs. J Adv Nurs 
[Internet]. 2019 Jan 1 [cited 2019 Nov 30];75(1):234-52. Available from: http://doi.wiley.com/10.1111/jan.13851

5 . Worley J, Heyland M. Evaluating competency based education modules in an online nurse practitioner course. J Nurs Educ Pract. 2019;9(3).

6. Bogossian FE, Cant RP, Ballard EL, Cooper SJ, Levett-Jones TL, McKenna LG, et al. Locating "gold standard" evidence for simulation as a substitute for clinical practice in prelicensure health professional education: A systematic review. J Clin Nurs [Internet]. 2019 Nov 13 [cited 2019 Nov 30];28(21-22):3759-75. Available from:

https://onlinelibrary.wiley.com/doi/abs/10.1111/jocn.14965

7. Bennett CJ, Walston SL. Improving the Use of Competencies in Public Health Education. Am J Public Health [Internet]. 2015;105(S1):S65-7. Available from: https://search-proquestcom.proxy.lib.ul.ie/docview/1660150371?accountid=14564\&rfr_id=info\%3Axri\%2Fsid\%3Aprimo

8. Steigerwald D, Nolan C, Loux T, Baskin CR, Scharff DP. Improving public health competencies through required practice experience. Public Health [Internet]. 2016 [cited 2019 Nov 30];140:265-7. Available from: http://dx.doi.org/10.1016/j.puhe.2016.07.001

9. Ramaswamy R, Mosnier J, Reed K, Powell BJ, Schenck AP. Building capacity for Public Health 3.0: introducing implementation science into an MPH curriculum. [cited 2019 Nov 30]; Available from: https://doi.org/10.1186/s13012-019-0866-6

10. Hernandez KE, Bejarano S, Reyes FJ, Chavez M, Mata H. Experience Preferred: Insights From Our Newest Public Health Professionals on How Internships/Practicums Promote Career Development. Health Promot Pract [Internet]. 2014 Jan 22 [cited 2019 Dec 1];15(1):95-9. Available from: http://journals.sagepub.com/doi/10.1177/1524839913507578

11. Sullivan, Lisa M, Velez, Amanda, Edouard, VM, Galea S. Realigning the Master of Public Health (MPH) to Meet the Evolving Needs of the Workforce. Perspect Pedagog [Internet]. 2017 [cited 2019 Nov 30]; Available from: https://doi.org/10.1177/2373379917746698

12. Arksey H, O'Malley L. Scoping studies: towards a methodological framework. Int J Soc Res Methodol [Internet]. 2005 Feb [cited 2019 Dec 4];8(1):19-32. Available from: http://www.tandfonline.com/doi/abs/10.1080/1364557032000119616

13. Levac D, Colquhoun H, O'Brien KK. Scoping studies: advancing the methodology. Implement Sci [Internet]. 2010 Dec 20 [cited 2019 Dec 4];5(1):69. Available from: http://implementationscience.biomedcentral.com/articles/10.1186/1748-5908-5-69

14. Villanueva AM, Hovinga ME, Cass JL. Master of Public Health Community-Based Practicum. J Public Heal Manag Pract [Internet]. 2011 [cited 2020 Feb 9];17(4):337-43. Available from: http://content.wkhealth.com/linkback/openurl?sid=WKPTLP:landingpage\&an=00124784201107000-00009

15. Boelen C. Coordinating medical education and health care systems: the power of the social accountability approach. Med Educ [Internet]. 2018 Jan;52(1):96-102. Available from: https://search.ebscohost.com/login.aspx?direct=true\&db=ccm\&AN=126850459\&site=ehost-live 
16. Global Consensus for Social Accountability of Medical Schools [Internet]. [cited 2020 Mar 23]. Available from: https://healthsocialaccountability.org/

17. Goodman J. Virtual practicums within an MPH program: a career development case study. Health Promot Pract [Internet]. 2015 Jan 20 [cited 2020 Feb 9];16(1):7-11. Available from: http://journals.sagepub.com/doi/10.1177/1524839914555572

18. Brambleby P, Coates R. Learning contracts in higher professional training: a user's guide. Postgrad Med J. 1997;73(859):279-82.

19. Harden RM. Developments in outcome-based education. Med Teach [Internet]. 2002 Jan 3 [cited 2020 Feb 23];24(2):117-20. Available from:

http://www.tandfonline.com/doi/full/10.1080/01421590220120669

20. APHEA - Core Curriculum Areas [Internet]. [cited 2020 Mar 7]. Available from: https://www.aphea.be/Pages/A2.CURRICULA/Curriculum_core_areas.html

21. Calhoun JG, Ramiah K, Weist EM, Shortell SM. Development of a core competency model for the master of public health degree. Am J Public Health [Internet]. 2008 Sep 10 [cited 2020 Feb 23];98(9):1598-607. Available from: http://ajph.aphapublications.org/doi/10.2105/AJPH.2007.117978

22. Schuster W, Stevens KB. Supervising Practicum Students. Teach Educ Spec Educ J Teach Educ Div Counc Except Child [Internet]. 1991 Jul 1 [cited 2020 Feb 23];14(3):169-76. Available from: http://journals.sagepub.com/doi/10.1177/088840649101400303

23. Beck C, Kosnik C. Professors and the Practicum. J Teach Educ [Internet]. 2002 Jan 2 [cited 2020 Feb 23];53(1):6-19. Available from: http://journals.sagepub.com/doi/10.1177/0022487102053001002

24. Carraccio C, Englander R, Holmboe ES, Kogan JR. Driving Care Quality Aligning Trainee Assessment and Supervision Through Practical Application of Entrustable Professional Activities, Competencies, and Milestones. Acad Med [Internet]. 2016 Feb [cited 2020 Feb 23];91(2):199-203. Available from: http://content.wkhealth.com/linkback/openurl?sid=WKPTLP:landingpage\&an=00001888201602000-00020

25. Landmark BT, Hansen GS, Bjones I, BOhler A. Clinical supervision - factors defined by nurses as influential upon the development of competence and skills in supervision. J Clin Nurs [Internet]. 2003 Nov 1 [cited 2020 Feb 23];12(6):834-41. Available from: http://doi.wiley.com/10.1046/j.13652702.2003.00813.x

26. Cashman SB, Seifer SD. Service-Learning: An Integral Part of Undergraduate Public Health. Am J Prev Med [Internet]. 2008 Sep 1 [cited 2019 Dec 4];35(3):273-8. Available from: https://www.sciencedirect.com/science/article/abs/pii/S0749379708005151

\section{Tables}

Table 1. Characteristics of Universities reviewed $(n=35)$ 


\begin{tabular}{|l|l|l|}
\hline Characteristic & Number & Percent \\
\hline Geographical Region & 5 & 14 \\
\hline Africa & 5 & 14 \\
\hline Asia & 5 & 14 \\
\hline Australia & 5 & 14 \\
\hline Canada & 5 & 14 \\
\hline European Union & 5 & 14 \\
\hline United Kingdom & 5 & 14 \\
\hline United States & \multicolumn{2}{|l|}{} \\
\hline Accrediting Body & 6 & 17 \\
\hline Council on Education for Public Health (CEPH) & 2.75 \\
\hline Training Program in Epidemiology and Public Health Interventions Network (TEPHINET) & 1 & 2.75 \\
\hline International Union for Health Promotion (IUHP) & 1 & 9 \\
\hline Agency for Public Health Education Accreditation (APHEA) & 3 & 6 \\
\hline Netherlands Flemish Accreditation Organization (NVAO) & 2 & 6 \\
\hline Ministry of Education & 2 & 57 \\
\hline No Accrediting Body & 20 \\
\hline Program Duration & \multicolumn{2}{|l|}{} \\
\hline 12 months or less & 12 & 34 \\
\hline $13-24$ months & 23 & 66 \\
\hline
\end{tabular}

Table 2. Structural Characteristics of GPH Practicums reviewed $(n=35)$ 


\begin{tabular}{|c|c|c|}
\hline Characteristic & Number & Percentage \\
\hline \multicolumn{3}{|l|}{ Prerequisites required prior to practicum initiation } \\
\hline Prerequisite courses required & 11 & 31 \\
\hline Prerequisite courses not listed & 24 & 69 \\
\hline \multicolumn{3}{|l|}{ Timing of practicum scheduling } \\
\hline Semester 2 & 3 & 9 \\
\hline Semester 3 / Summer & 13 & 37 \\
\hline Year 2 & 11 & 31 \\
\hline Variable term/Undefined & 8 & 23 \\
\hline \multicolumn{3}{|l|}{ Practicum Duration } \\
\hline 50-100 hours & 2 & 6 \\
\hline $101-200$ hours & 4 & 11 \\
\hline 201 or more hours & 1 & 3 \\
\hline $4-8$ weeks & 6 & 17 \\
\hline $9-12$ weeks & 9 & 26 \\
\hline $13-16$ weeks & 6 & 17 \\
\hline Practicum duration not defined & 10 & 28 \\
\hline \multicolumn{3}{|l|}{ Contact hours } \\
\hline Stated minimum number contact hours only & 6 & 17 \\
\hline Stated minimum \& maximum number contact hours & 2 & 6 \\
\hline Contact time measured in weeks & 17 & 49 \\
\hline Contact time not specified & 10 & 28 \\
\hline \multicolumn{3}{|l|}{ Credit hours } \\
\hline No credit hours for practicum & 1 & 3 \\
\hline Fixed number of credit hours for practicum & 32 & 91 \\
\hline Practicum credit hours not provided & 2 & 6 \\
\hline \multicolumn{3}{|l|}{ Ratio of credits to overall degree } \\
\hline No credit hours for practicum & 1 & 3 \\
\hline 1-10 percent overall credits & 8 & 22 \\
\hline $11-20$ percent overall credits & 15 & 43 \\
\hline 21-30 percent overall credits & 3 & 9 \\
\hline 31-40 percent overall credits & 5 & 14 \\
\hline Information unavailable & 3 & 9 \\
\hline
\end{tabular}

Table 3. Domains of GPH Practicums reviewed $(n=35)$ 


\begin{tabular}{|c|c|c|}
\hline Domain & Number & Percentage \\
\hline \multicolumn{3}{|l|}{ COMPETENCIES: } \\
\hline \multicolumn{3}{|l|}{ Core Competencies } \\
\hline Core public health competencies listed & 20 & 57 \\
\hline Core public health competencies not listed & 15 & 43 \\
\hline \multicolumn{3}{|l|}{ Practicum Specific Competencies } \\
\hline Practicum specific competencies defined & 8 & 23 \\
\hline Practicum specific competencies referenced, undefined & 1 & 3 \\
\hline Practicum specific competencies not listed/missing & 26 & 74 \\
\hline \multicolumn{3}{|l|}{ SUPERVISION: } \\
\hline \multicolumn{3}{|l|}{ Practicum Supervisor Criteria } \\
\hline Stated criteria to define appropriate supervisor & 13 & 37 \\
\hline No criteria listed to define appropriate supervisor & 23 & 63 \\
\hline \multicolumn{3}{|l|}{ Practicum Supervisor Responsibilities } \\
\hline Stated responsibilities of practicum supervisor & 12 & 34 \\
\hline Did not state responsibilities of practicum supervisor & 23 & 66 \\
\hline \multicolumn{3}{|l|}{ WRITTEN AGREEMENT \& OBJECTIVES: } \\
\hline \multicolumn{3}{|l|}{ Written agreement } \\
\hline Written agreement required & 14 & 40 \\
\hline Written agreement not referenced & 21 & 60 \\
\hline \multicolumn{3}{|l|}{ Practicum Objectives } \\
\hline Objectives included in the written agreement & 12 & 34 \\
\hline Objectives not included/unclear if in written agreement & 2 & 6 \\
\hline Practicum objectives defined & 29 & 83 \\
\hline \multicolumn{3}{|l|}{ Final Deliverables (multiple per program) } \\
\hline No requirement & 0 & 0 \\
\hline Oral presentation & 13 & 37 \\
\hline Written report & 17 & 49 \\
\hline Portfolio/Reflections & 3 & 8 \\
\hline Poster/Abstract & 5 & 14 \\
\hline Practicum-specific deliverables & 16 & 46 \\
\hline Not listed/unclear requirement & 6 & 17 \\
\hline \multicolumn{3}{|l|}{ ASSESSMENT } \\
\hline \multicolumn{3}{|l|}{ Assessment Intervals } \\
\hline Pre-practicum (learning agreement) & 14 & 40 \\
\hline Mid-practicum & 9 & 26 \\
\hline Post-practicum & 21 & 60 \\
\hline Assessment information not available & 9 & 26 \\
\hline \multicolumn{3}{|l|}{ Final Grading System } \\
\hline Pass/fail & 8 & 23 \\
\hline Letter grade & 7 & 20 \\
\hline No grade/unclear & 20 & 57 \\
\hline
\end{tabular}

Table 4. Practicum Supervisor Requirements $(n=13)$ 


\begin{tabular}{|l|l|l|}
\hline Criteria defined & Number & Percentage \\
\hline Expertise in project area & 5 & 38 \\
\hline Experience \& status within the organization & 5 & 38 \\
\hline Interest \& competence in supervising \& mentoring & 5 & 38 \\
\hline Professional credentialing & 8 & 62 \\
\hline 3-5 years experience with advanced Master or Doctoral degree & 1 & 8 \\
\hline $\begin{array}{l}10 \text { years experience with Bachelor degree or equivalent combination of education and } \\
\text { experience }\end{array}$ & 4 & 30 \\
\hline MPH or Master degree in the related field & 1 & 8 \\
\hline
\end{tabular}

Table 5. Descriptive Terminology for Practical Placements $(n=35)$

\begin{tabular}{|l|l|l|}
\hline Terms Used & Number & Percentage \\
\hline Practicum/Workplace Practicum & 14 & 40 \\
\hline Applied Practical Experience & 2 & 6 \\
\hline Internship/Practice Internship & 7 & 20 \\
\hline Residency & 2 & 6 \\
\hline Placement/Professional Placement & 3 & 8 \\
\hline Project in Public Health & 1 & 2.75 \\
\hline Pathways to Public Health in the Workplace & 1 & 2.75 \\
\hline Community Placement Module & 1 & 2.75 \\
\hline Professional Practice & 1 & 2.75 \\
\hline Professional Project & 1 & 2.75 \\
\hline Field Study/Work & 2 & 6 \\
\hline
\end{tabular}

Table (6) Relationship between competencies, objectives \& deliverables in practicum design

\begin{tabular}{|l|l|}
\hline Competencies & $\begin{array}{l}\text { Competencies are the central knowledge, skills and attitudes necessary for the public health } \\
\text { workforce to practice effectively and achieve the core functions of public healthare. Competencies } \\
\text { define aptitudes or educational outcomes students must acquire upon completion of a GPH } \\
\text { program. }\end{array}$ \\
\hline Objectives & $\begin{array}{l}\text { Objectives are actionable goals developed by the student in conjunction with the onsite practicum } \\
\text { supervisor and university based practicum coordinator. Objective development is based on } \\
\text { educational outcomes defined by the program core competencies. }\end{array}$ \\
\hline Deliverables & $\begin{array}{l}\text { Deliverables are tangible work products created by the student during the course of the } \\
\text { practicum. Deliverables are informed by objectives which are developed based on competencies. }\end{array}$ \\
\hline
\end{tabular}

\section{Figures}




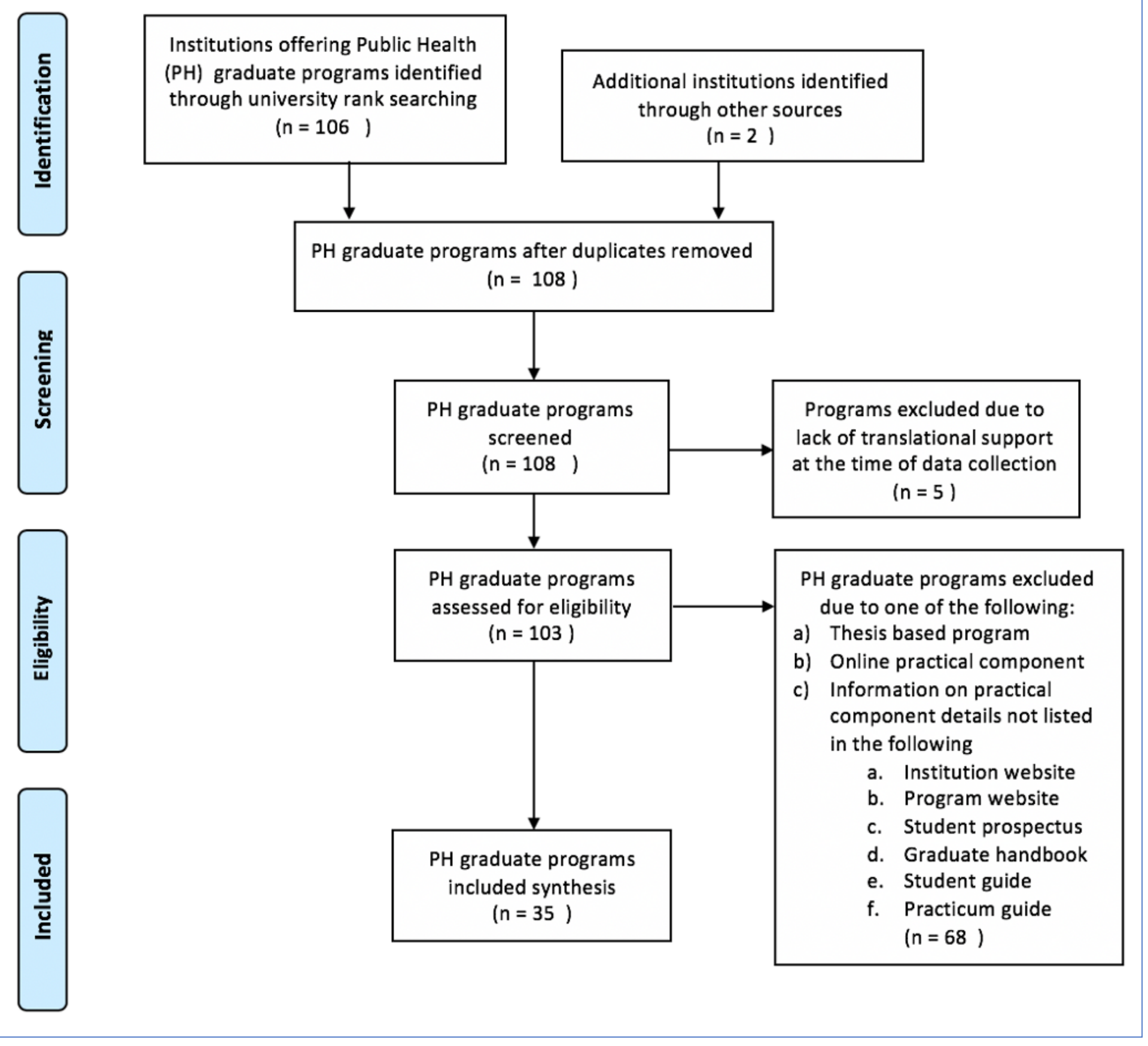

Figure 1

PRISMA flow diagram outlining the process of public health program selection for the sample.The PRIMSA diagram details our search and selection process applied during the research. 